\title{
Local Therapies Can Improve Intracerebral Control in Patients with Cerebral Metastasis from Gynecological Cancers
}

\author{
LIESA DZIGGEL ${ }^{1}$, STEFAN JANSSEN ${ }^{1,2}$, AMIRA BAJROVIC $^{3}$, THEO VENINGA ${ }^{4}$, \\ NGO THUY TRANG ${ }^{5}$, MAI TRONG KHOA ${ }^{5,6}$, STEVEN E. SCHILD ${ }^{7}$ and DIRK RADES ${ }^{1}$ \\ ${ }^{1}$ Department of Radiation Oncology, University of Lübeck, Lübeck, Germany; \\ ${ }^{2}$ Medical Practice for Radiotherapy and Radiation Oncology, Hannover, Germany; \\ ${ }^{3}$ Department of Radiotherapy, University Medical Center Eppendorf, Hamburg, Germany; \\ ${ }^{4}$ Department of Radiotherapy, Dr. Bernard Verbeeten Institute, Tilburg, the Netherlands; \\ ${ }^{5}$ Nuclear Medicine and Oncology Center, Bach Mai Hospital, Hanoi, Vietnam; \\ ${ }^{6}$ Department of Nuclear Mediciume, Hanoi Medical University, Hanoi, Vietnam; \\ ${ }^{7}$ Department of Radiation Oncology, Mayo Clinic, Scottsdale, AZ, U.S.A.
}

\begin{abstract}
Background/Aim: Patients with gynecological malignancies account for $2 \%$ of patients with cerebral metastases. Many patients receive whole-brain irradiation (WBI) alone. Local therapies (resection, stereotactic radiosurgery (SRS)) are becoming more popular. This study compared intracerebral control after local therapy to WBI alone in patients with gynecological malignancies. Patients and Methods: Of 56 patients, 45 received WBI alone, 6 SRS alone and 5 resection plus WBI. Treatment type, age, performance score, cancer site, number of cerebral lesions, metastases outside the brain, recursive partitioning analysis (RPA) class and period from gynecological cancer diagnosis to brain metastasis treatment were evaluated. Results: On univariate analyses, local therapy $(p=0.003)$, single cerebral lesion $(p<0.001)$ and RPA class $1 / 2$ $(p=0.027)$ were positively related to intracerebral control. On Cox regression analysis, local therapy $(p=0.013)$ and RPA class 1/2 ( $p=0.014)$ were significant. Conclusion: Local therapies led to better intracerebral control than WBI alone and should be considered for brain metastasis from gynecological malignancies whenever reasonable.
\end{abstract}

Brain metastasis is a relatively common complication that cancer patients experience during the process of their disease (1). Patients with brain metastasis from gynecological

Correspondence to: Prof. Dirk Rades, MD, Department of Radiation Oncology, University of Lübeck, Lübeck, Ratzeburger Allee 160, 23538 Lübeck, Germany. Tel: +49 4515006661, Fax: +49 4515003324, e-mail: rades.dirk@gmx.net

Key Words: Gynecological cancers, cerebral metastasis, whole-brain irradiation, stereotactic radiosurgery, neurosurgical resection, intracerebral control. malignancies are less common. They account for approximately $2 \%$ of all cancer patients in whom cerebral metastases are diagnosed. The vast majority of these patients are treated with irradiation, mainly in the form of whole-brain irradiation (WBI) alone (1). However, local therapies, such as neurosurgical resection and stereotactic radiosurgery (SRS) have become more popular for several years, particularly for patients with a limited number of up to five brain lesions. One major goal of using a local therapy, particularly when administered without WBI, is to decrease treatment-related toxicity, mainly a decline in neuro-cognitive function, by delivering a lower radiation dose to major parts of the brain (2). Another important end-point is intracerebral control, which is defined as freedom from new and/or progressive treated cerebral lesions. A recurrence within the brain has been identified as one major cause of decreased neurocognitive function and must, therefore, be avoided as long as possible (3-5). Studies of patients with one to three brain metastases from many different cancer types suggested that SRS alone and resection followed by WBI were superior to WBI alone regarding intracerebral control (6-8). However, since cancer types respond differently to irradiation, it would be important to see whether this also applies to cancers that are considered not very radiosensitive. Therefore, this study was initiated, which evaluates intracerebral control rates after local therapy and compares them to intracerebral control rates after WBI alone, specifically in patients with cerebral metastases from a gynecological malignancy.

\section{Patients and Methods}

A cohort of 56 patients irradiated for metastases to the brain were included in this retrospective study. Of these, 45 patients received WBI alone, 6 patients SRS alone and 5 patients neurosurgical 
Table I. Variables included in the analyses of intracerebral control.

\begin{tabular}{|c|c|c|}
\hline & $\begin{array}{l}\text { Number } \\
\text { of patients }\end{array}$ & $\begin{array}{c}\text { Proportion } \\
\text { of patients }(\%)\end{array}$ \\
\hline \multicolumn{3}{|l|}{ Type of treatment } \\
\hline WBI alone & 45 & 80 \\
\hline SRS alone & 6 & 11 \\
\hline Surgery+WBI & 5 & 9 \\
\hline \multicolumn{3}{|l|}{ Age } \\
\hline$\leq 62$ years & 28 & 50 \\
\hline$\geq 63$ years & 28 & 50 \\
\hline \multicolumn{3}{|l|}{ ECOG score } \\
\hline $1-2$ & 17 & 30 \\
\hline $3-4$ & 39 & 70 \\
\hline \multicolumn{3}{|l|}{ Cancer site } \\
\hline Ovary & 31 & 55 \\
\hline Uterus & 14 & 25 \\
\hline Cervix & 8 & 14 \\
\hline Vulva & 3 & 5 \\
\hline \multicolumn{3}{|c|}{ Number of cerebral lesions } \\
\hline 1 & 17 & 30 \\
\hline$\geq 2$ & 39 & 70 \\
\hline \multicolumn{3}{|c|}{ Metastases ouside the brain } \\
\hline No & 16 & 29 \\
\hline Yes & 40 & 71 \\
\hline \multicolumn{3}{|l|}{ RPA class } \\
\hline 1 & 9 & 16 \\
\hline 2 & 24 & 43 \\
\hline 3 & 23 & 41 \\
\hline \multicolumn{3}{|c|}{$\begin{array}{l}\text { Period from diagnosis of gynecological } \\
\text { cancer to treatment of brain metastasis }\end{array}$} \\
\hline$\leq 24$ months & 27 & 48 \\
\hline$\geq 25$ months & 29 & 52 \\
\hline
\end{tabular}

WBI, Whole-brain irradiation; SRS, stereotactic radiosurgery; ECOG, Eastern Cooperative Oncology Group; RPA, recursive partitioning analysis.

resection supplemented by WBI. SRS and neurosurgical resection were defined as local therapies. The type of treatment plus seven other variables (Table I) were investigated for intracerebral control. Other variables included age ( $\leq 62$ versus $\geq 63$ years, median $=62.5$ ), performance score according to the Eastern Cooperative Oncology Group (ECOG) (1-2 versus 3-4), cancer site (ovary versus uterus versus cervix versus vulva), number of cerebral lesions (single versus multiple ( $\geq 2$ ) lesions), metastases outside the brain (no versus yes), recursive partitioning analysis (RPA) class (1 versus 2 versus 3$)$ and period from initial diagnosis of gynecological cancer to treatment of brain metastasis ( $\leq 24$ versus $\geq 25$ months, median $=25$ ).

RPA class 1 is defined as a Karnofsky performance score of 70 or more plus three other favorable prognostic factors, namely age less than 65 years, controlled primary tumor and no systemic metastases outside the brain (9). RPA class 2 patients have a Karnofsky performance score of 70 or more but less than all three other favorable factors. Patients belonging to RPA class 3 have a Karnofsky performance score of less than 70 , regardless of the three other prognostic factors.
Table II. Results of the univariate analyses of intracerebral control.

\begin{tabular}{|c|c|c|c|c|}
\hline & $\begin{array}{c}\text { At } \\
3 \text { months }\end{array}$ & $\begin{array}{c}\text { At } \\
6 \text { months }\end{array}$ & $\begin{array}{c}\text { At } \\
12 \text { months }\end{array}$ & $p$ \\
\hline \multicolumn{5}{|l|}{ Type of treatment } \\
\hline WBI alone & 76 & 50 & 30 & \\
\hline SRS alone & 100 & 100 & 100 & \\
\hline Surgery + WBI & 100 & 100 & 100 & 0.003 \\
\hline \multicolumn{5}{|l|}{ Age } \\
\hline$\leq 62$ years & 88 & 60 & 36 & \\
\hline$\geq 63$ years & 74 & 61 & 61 & 0.65 \\
\hline \multicolumn{5}{|l|}{ ECOG score } \\
\hline $1-2$ & 100 & 81 & 61 & \\
\hline $3-4$ & 72 & 52 & 52 & 0.09 \\
\hline \multicolumn{5}{|l|}{ Cancer site } \\
\hline Ovary & 86 & 63 & 50 & \\
\hline Uterus & 70 & 61 & 41 & \\
\hline Cervix & 73 & 44 & 44 & \\
\hline Vulva & 100 & 100 & 100 & 0.33 \\
\hline \multicolumn{5}{|c|}{ Number of cerebral lesions } \\
\hline 1 & 100 & 90 & 90 & \\
\hline$\geq 2$ & 73 & 48 & 24 & $<0.001$ \\
\hline \multicolumn{5}{|c|}{ Metastases ouside the brain } \\
\hline No & 89 & 74 & 56 & \\
\hline Yes & 78 & 55 & 55 & 0.07 \\
\hline \multicolumn{5}{|l|}{ RPA class } \\
\hline 1 & 100 & 78 & 47 & \\
\hline 2 & 91 & 72 & 72 & \\
\hline 3 & 61 & 41 & $\mathrm{n} / \mathrm{a}$ & 0.027 \\
\hline \multicolumn{5}{|c|}{$\begin{array}{l}\text { Period from diagnosis } \\
\text { of gynecological cancer to } \\
\text { treatment of brain metastasis }\end{array}$} \\
\hline$\leq 24$ months & 76 & 61 & 37 & \\
\hline$\geq 25$ months & 86 & 62 & 62 & 0.30 \\
\hline
\end{tabular}

WBI, Whole-brain irradiation; SRS, stereotactic radiosurgery; ECOG, Eastern Cooperative Oncology Group; RPA, recursive partitioning analysis; $\mathrm{n} / \mathrm{a}$, not available; bold, significant value.

Initially, all eight variables were analyzed in a univariate manner using Kaplan-Meier analyses. Comparisons of the corresponding curves were performed with the log-rank test. Significant (defined as $p<0.05$ ) variables were included in a Cox regression model.

\section{Results}

According to the univariate analyses, three variables showed a significantly positive association with better intracerebral control (Table II). These variables included administration of a local therapy $(p=0.003)$, presence of only a single cerebral lesion $(p<0.001)$ and RPA class 1 or $2(p=0.027)$. According to the Cox regression model, administration of a local therapy (risk ratio $=2.02 \times 10^{-5}, p=0.013$ ) and RPA class 1 or 2 (risk ratio=2.36, $p=0.014$ ) were independent predictors of intracerebral control, whereas presence of a single cerebral lesion was no longer significant (risk ratio $=1.28, p=0.32$ ). 


\section{Discussion}

Since patients with metastatic gynecological cancer generally experience poor prognoses, considerable efforts have been made to achieve improvement, including new systemic agents, novel surgical approaches and modern radiotherapy techniques (10-16). In case of brain metastases, most patients are treated with WBI alone (1). However, local therapies, namely surgical resection and stereotactic radiosurgery, have gained importance, particularly for patients with few lesions.

In 2004, a randomized trial of patients with one to three cerebral metastases has shown that WBI plus SRS resulted in significantly better survival than WBI alone in the subgroup of patients with a single lesion (8). Median survival times were 6.5 months and 4.9 months, respectively $(p=0.039)$. However, this trial included patients with brain metastasis from many different cancer types. Moreover, intracerebral control, which is also an important end-point, was not investigated. Intracerebral control was investigated in a retrospective study of 186 patients with one to three brain lesions that compared SRS alone to WBI alone (6). According to multivariate analysis, SRS led to significantly better intracerebral control (risk ratio $=1.33, p=0.003$ ). In another retrospective study of 195 patients with a single cerebral lesion, WBI plus upfront resection was superior to WBI alone regarding intracerebral control (risk ratio $=1.24, p<0.001$ ) (7). However, the latter two studies included patients with brain metastasis from different cancer types as well. Because cancers vary considerably with respect to radio-sensitivity, it appears reasonable to evaluate the value of local therapies for brain metastasis treatment separately for different types of cancer or small groups of related cancer types. This study focused specifically on patients with cerebral metastases from gynecological malignancies and compared local therapies to WBI alone for intracerebral control. According to its results, SRS and neurosurgery plus WBI both resulted in excellent long-term intracerebral control rates of $100 \%$ at 12 months. These rates were significantly better than after WBI alone, which resulted in intracerebral control rates of only $50 \%$ at 6 months and $30 \%$ at 12 months, respectively. Thus, local therapies should be considered for these patients whenever reasonable. Surgical resection should be limited to a single lesion that is not located close to the brainstem or other critical structures (1). SRS is usually recommended only for patients with a limited number of up to five cerebral lesions with a maximum diameter of 3-4 $\mathrm{cm}(1,12)$. If these criteria are met, patients with brain metastases from a gynecological malignancy can benefit from administration of a local therapy in terms of better intracerebral control. Intracerebral control is an important end-point, which is also very important for preserving the patient's neuro-cognitive function.
In summary, local therapies, namely neurosurgical resection and SRS, contributed to better intracerebral control when compared WBI alone. Thus, local therapies should be considered for the treatment of brain metastasis from gynecological malignancies whenever the criteria for their indication are met.

\section{Conflicts of Interest}

On behalf of all Authors, the corresponding Author states that there is no conflict of interest related to this study.

\section{References}

1 Tsao MN, Rades D, Wirth A, Lo SS, Danielson BL, Gaspar LE, Sperduto PW, Vogelbaum MA, Radawski JD, Wang JZ, Gillin MT, Mohideen N, Hahn CA and Chang EL: Radiotherapeutic and surgical management for newly diagnosed brain metastasis(es): An American Society for Radiation Oncology evidence-based guideline. Pract Radiat Oncol 2: 210-25, 2012.

2 Chang EL, Wefel JS, Hess KR, Allen PK, Lang FF, Kornguth DG, Arbuckle RB, Swint JM, Shiu AS, Maor MH and Meyers CA: Neurocognition in patients with brain metastases treated with radiosurgery or radiosurgery plus whole-brain irradiation: a randomised controlled trial. Lancet Oncol 10: 1037-1044, 2009.

3 Aoyama H, Tago M, Kato N, Toyoda T, Kenjyo M, Hirota S, Shioura H, Inomata T, Kunieda E, Hayakawa K, Nakagawa K, Kobashi $G$ and Shirato $H$ : Neurocognitive function of patients with brain metastasis who received either whole brain radiotherapy plus stereotactic radiosurgery or radiosurgery alone. Int J Radiat Oncol Biol Phys 68: 1388-1395, 2007.

4 Regine WF, Scott C, Murray K and Curran W: Neurocognitive outcome in brain metastases patients treated with acceleratedfractionation vs. accelerated-hyperfractionated radiotherapy: an analysis from Radiation Therapy Oncology Group Study 91-04. Int J Radiat Oncol Biol Phys 51: 711-717, 2001.

5 Meyers CA, Smith JA, Bezjak A, Mehta MP, Liebmann J, Illidge T, Kunkler I, Caudrelier JM, Eisenberg PD, Meerwaldt J, Siemers R, Carrie C, Gaspar LE, Curran W, Phan SC, Miller RA and Renschler MF: Neurocognitive function and progression in patients with brain metastases treated with whole-brain radiation and motexafin gadolinium: results of a randomized phase III trial. J Clin Oncol 22: 157-165, 2014.

6 Rades D, Pluemer A, Veninga T, Hanssens P, Dunst J and Schild SE: Whole-brain radiotherapy versus stereotactic radiosurgery for patients in recursive partitioning analysis classes 1 and 2 with 1 to 3 brain metastases. Cancer 110: 2285-2292, 2007.

7 Rades D, Kieckebusch S, Haatanen T, Lohynska R, Dunst J and Schild SE: Surgical resection followed by whole brain radiotherapy versus whole brain radiotherapy alone for single brain metastasis. Int J Radiat Oncol Biol Phys 70: 1319-1324, 2008.

8 Andrews DW, Scott CB, Sperduto PW, Flanders AE, Gaspar LE, Schell MC, Werner-Wasik M, Demas W, Ryu J, Bahary JP, Souhami L, Rotman M, Mehta MP and Curran WJ Jr.: Whole brain radiation therapy with or without stereotactic radiosurgery boost for patients with one to three brain metastases: phase III results of the RTOG 9508 randomised trial. Lancet 363: 16651672, 2004. 
9 Gaspar L, Scott C, Rotman M, Asbell S, Phillips T, Wasserman T, McKenna WG and Byhardt R: Recursive partitioning analysis (RPA) of prognostic factors in three Radiation Therapy Oncology Group (RTOG) brain metastases trials. Int J Radiat Oncol Biol Phys 37: 745-751, 1997.

10 Fanfani F, Fagotti A, Ercoli A, Gallotta V, Chiantera V, Restaino S, Monterossi G and Scambia G: Is There a role for tertiary (TCR) and quaternary (QCR) cytoreduction in recurrent ovarian cancer? Anticancer Res 35: 6951-6955, 2015.

11 Bacalbaşa N, Balescu I, Dima S and Popescu I: Long-term survivors after liver resection for ovarian cancer liver metastases. Anticancer Res 35: 6919-6923, 2015.

12 Rades D, Huttenlocher S, Rudat V, Hornung D, Blanck O, Phuong PC, Khoa MT, Schild SE and Fischer D: Radiosurgery with 20 Gy provides better local contol of 1-3 brain metastases from breast cancer than with lower doses. Anticancer Res 35: 333-336, 2015.

13 Chekerov R, Kaltenecker G, Reichert D, Göhler T, Klare P, Oskay-Özcelik G, Sauer U, Wischnik A, Vehling-Kaiser U, Becker M, Hutzschenreuter U, Ammon A, Heidrich-Lorsbach E and Sehouli J: Treosulfan in the treatment of advanced ovarian cancer - Results of a German multicenter non-interventional study. Anticancer Res 35: 6869-6875, 2015.
14 Yamane T, Asanoma K, Kobayashi H, Liu G, Yagi H, Ohgami $\mathrm{T}$, Ichinoe A, Sonoda K, Wake $\mathrm{N}$ and Kato K: Identification of the critical site of calponin 1 for suppression of ovarian cancer properties. Anticancer Res 35: 5993-5999, 2015.

15 Bacalbasa N, Balescu I, Dima S, Brasoveanu V and Popescu I: Hematogenous splenic metastases as an independent negative prognosis factor at the moment of primary cytoreduction in advanced stage epithelial ovarian cancer - A single center experience. Anticancer Res 35: 5649-5654, 2015.

16 Hata M, Miyagi E, Koike I, Numazaki R, Asai-Sato M, Kasuya T, Kaizu H, Mukai Y, Hirahara F and Inoue T: Radiation therapy for para-aortic lymph node metastasis from uterine cervical cancer. Anticancer Res 35: 4849-4854, 2015.
Received June 28, 2016

Revised July 11, 2016

Accepted July 12, 2016 